\title{
The Effect of Rise Angle of V-Hull Non Ballast Ship on Seakeeping Performance
}

\author{
HESHAM ELKADY ${ }^{1, a^{*}}$, Prof. HAN DUANFENG ${ }^{1}$ and Prof. GAO LIANGGAO ${ }^{1}$ \\ ${ }^{1}$ Harbin Engineering University, College of Shipbuilding Engineering, China, 150001
}

\begin{abstract}
In this paper a new concept in ship design was used to be alternative of ballast water system, to emerge that remedy the introduction of invasive marine species and the disadvantages of ballast water treatment systems. Thus, the hydrodynamic influences due to hull line variation of this kind of ships were studied, using the invariant cross-section area curve under the design draft to change the rise angle at bottom. Then numerical calculation was used to get the seakeeping at each angle. Two 3D models were constructed for 59000 DWT oil tankers and 35000 DWT bulk carriers, where the result of the bulk carrier was exposed.
\end{abstract}

\section{Introduction}

The storm ballast only (NOBS) concept was invented as one of No ballast or Zero discharge methods of a ballast-free ships to overcome the introduction of invasive marine species and the disadvantages of ballast water treatment systems.

The Non-Ballast ship has been studied abroad, but it is rarely mentioned in China. In this paper, the hydrodynamic effect by changing the rise angle of $\mathrm{V}$ shaped hull at ship's bottom with a wider breadth, while the major factors such as mid-section area, length, draught, displacement etc. were kept unchanged. In the present research, the hydrodynamic aspects of NonBallast concept were further investigated numerically using Maxsurf software to construct the 3D modeling and Seakeeper software to calculate and analyses the seakeeping performance.

\section{Background}

A ship, in particular, a cargo vessel is designed including the weight of a cargo on board etc. therefore, when the ship is in a partial load or unloaded condition, the ship would float too high, thereby making it unstable. In order to prevent these, Ballast tanks in hull are loaded with sea water, to maintain a necessary draught to ensure efficient propeller and rudder operation, safe navigation and to avoid bow slamming especially in heavy seas. Ballast water is also used to balance the ship as fuel is used up during a long voyage, or during loading and unloading operations.

The transportation and introduction of invasive marine species into new environments through ships' ballast water, attached to ships' hulls and via other vectors has been identified as one of the four greatest threats to the world's oceans as it cause damage to the environment and impacts on human health, social and economic[1]. Researches had targeted technologies that treat ballast water to remove or destroy the living organisms being carried including ballast water exchange, filtration, heat, ultra-violet light, ozone, de-oxygenation, electro ionization and chemical biocides, among others.

However all current treatment techniques would require high cost for installation of sensitive equipment and retrofit on a ship, extra-cost of operation, maintenance and training of the ship crew to operate, plus the cost of managing tank sediments. Also require more power which will result in more combustion of fuel and consequently bring more emission gasses and air pollution. In addition single treatment method would not provide an effective solution.

A new concept was invented to be alternative to ballast water system. The concept is based on a V-shaped hull which stems from new thinking about optimal hull shape and buoyancy distribution. The V-hull alters the vertical distribution of hull buoyancy, causing a deeper draught in the light (unloaded) condition than that of conventional hull. By widening the beam by $\sim 30 \%$, the ship's displacement can be kept at the same full load draught as that of an equivalent deadweight of conventional hull, while hull length is minimally altered.

The V-shape cross-section maintains sufficient unloaded draught and stability and avoid bow slamming and propeller racing without needing any ballast water (BW) for the majority of sea conditions. It also likely provides the potential for better vessel control, reduce hull resistance and improve propulsion efficiency for most speeds and sea conditions.

Overall, the investigation of the Non-Ballast (NoBS) Ship Concept has shown that it provides a viable alternative to the addition of costly ballast water

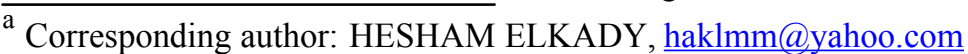


treatment systems in order to meet the evolving performance requirements for ballast water treatment. The concept essentially eliminates the transport of foreign ballast water, which should be more effective than current treatment methods in reducing the potential for the further introduction of nonindigenous aquatic species[2-4]

\section{Analysis and Determination of Main Dimensions}

In this paper, a 35000 DWT bulk carrier was selected as the mother ship, with principal dimensions shown at table
(Table 1), which was redesigned to be V-Hull NonBallast ship with same principal dimensions except the beam will increase due to change in the rise angle.

The rise angle at the bottom $\theta$ is altered with the change in beam, while the major factors unchanged according to equation (Eq.1) which is based on invariant cross-section area curve under the design draft as shown in figure (Fig.1), where the increased area B is equal to the reduced area A.[5]

The parallel middle body can be obtained by using transform method, while not parallel section by scaling transformation method using equation (Eq.2) as shown in figure (Fig.2).[5].

Table 1 The mother ship main principal dimensions

\begin{tabular}{|c|c|c|c|}
\hline Total length LOA & $180[\mathrm{~m}]$ & Design draft $T$ & $9.5[\mathrm{~m}]$ \\
\hline Length between perpendiculars LBP & $172[\mathrm{~m}]$ & Depth D & $14.7[\mathrm{~m}]$ \\
\hline
\end{tabular}

Table 2, the half breadth of design ship with different $\theta$

\begin{tabular}{ccccc}
\hline$\theta$ & $\mathrm{T}[\mathrm{m}]$ & $\mathrm{B}[\mathrm{m}]$ & Area $\mathrm{A}[\mathrm{m} 2]$ & Area B[m2] \\
\hline Mother ship & 9.5 & 15 & ------ & ------ \\
\hline $7.5^{\circ}$ & 9.5 & 17 & 14.816936 & 14.816936 \\
\hline $10^{\circ}$ & 9.5 & 18 & 19.844934 & 19.844934 \\
\hline $12.5^{\circ}$ & 9.5 & 19.4 & 24.951014 & 24.951014 \\
\hline $15^{\circ}$ & 9.5 & 21.5 & 30.15699 & 30.15699 \\
\hline
\end{tabular}

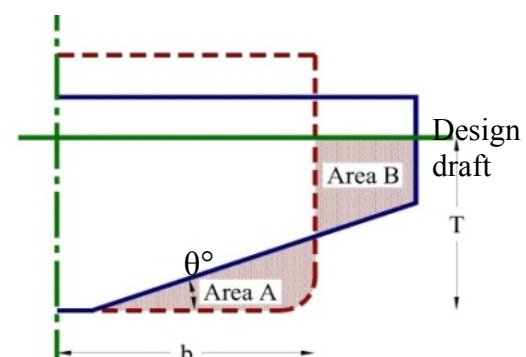

Figure 1, The invariant cross-section area

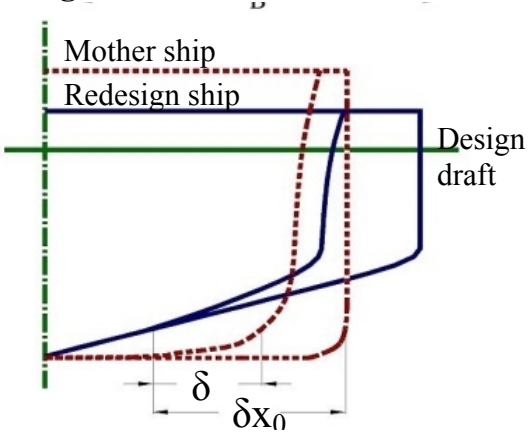

Figure 2, The scaling transformation method

$$
\begin{aligned}
& \mathrm{n}=\frac{-\mathrm{b}(\mathrm{b} \tan \theta-\mathrm{T}) \pm \sqrt{[2 \mathrm{~b}(\mathrm{~b} \tan \theta-\mathrm{T})]^{2}-4 \mathrm{~b}^{2} \tan \theta \times \mathrm{b}^{2} \tan \theta}}{2 \mathrm{~b}^{2} \tan \theta} \\
& \delta \mathrm{x}=\frac{\mathrm{L}-\mathrm{s}}{\mathrm{L}} \times \delta \mathrm{x}_{0}
\end{aligned}
$$

$$
\mathrm{x}=\mathrm{x}_{\mathrm{0}}+\delta \mathrm{x}
$$

Where $\mathrm{n}$ is the single coefficient range $(0<\mathrm{n}<1)$, $\mathrm{b}$ is the half breadth of conventional ship, $\mathrm{B}$ is the half breadth of design ship and equal $(n+1) b, \theta$ is the rise angle, $\delta x$ is the amount of the half-breadth change at any draft, $\mathrm{L}$ is the half of design length, $\mathrm{S}$ is the distance from the chosen station and nearest parallel middle body while $\mathrm{x}$ the half-breadth of design ship at any draft.

From equation (Eq.1) we can get the half breadth of design ship for changed $\theta$ between $5^{\circ}$ and $15^{\circ}$ as shown in table (Table 2) with constant draft $9.5[\mathrm{~m}]$, and from equations (Eq.2) and (Eq.3) the half-breadth of designed ship at any draft can be shown in (Fig 3).

\section{Numerical Investigation}

Seakeeping is the dynamic response of the ship affected by environmental forces, primarily wind and waves. The seakeeping performance affects the efficiency of the subsystems, including the crew, propulsion systems, command-control systems, and the weapon-sensor systems. So in ship design it is important to predetermine the behavior of the ship or floating structure when it is subjected to waves.

The commercial software Maxsurf is a powerful three-dimensional surface modeling system used in the field of marine design, which allows the use of multiple 
surfaces modeling in a given design, thus offers a wide scope for the creation of a wide range of hull forms. Combined with the built-in hydrostatic calculations, there are a couple of tools to experiment with shapes and explore design parameters. And Seakeeper software provides calculations and analyses of Response Amplitude Operators (RAO) at each angle of a ship hull, as it can import and measure Maxsurf designs automatically to obtain the required parameters[6].

The figure (Fig 4) shows the result for numerical investigation of seakeeping to achieve the NORDFORSK 1987 seakeeping criteria which is showed in table (Table 3)[7], for variation rise angle at bottom $\theta$ of model, in range of velocity from 0 to 14 [kts] and in sea stage 4 which characteristics as moderate waves (waves height 1.25 to 2.5 metres ( $4 \mathrm{ft} 1$ in to $8 \mathrm{ft} 2 \mathrm{in}$ )) according to world meteorological WMO.

\section{Conclusion}

From the previous plot of seakeeping speed polar diagrams, the following facts can be deduced. The ships response patterns for different rise angle at the bottom for models are nearly the same. That due to using of the invariant cross-section area curve under the design draft method to change the rise angle at bottom altered with the change in beam, while the major factors were kept unchanged as shown.

Length is important parameter in its own right, this can be appreciated by considering the response of a ship to a given wave system, if the ship is long compared with the component wave present, it will pitch and heave to a small extent only. And length to draught ratio which their high values lead to resonance with shorter waves and this effect can be quite marked, because of this the $\mathrm{L} / \mathrm{T}$ ratios lead to lower amplitudes of pitch and heave in long waves and greater amplitudes in short wave, a high $\mathrm{L} / \mathrm{T}$ ratio is more conductive to slamming[8], both are unchanged. While the forward waterplane area coefficient $\mathrm{CWF}$ which its increase reduces the relative motion at the bow but can lead to increased vertical wave bending moment. And prismatic coefficient $\mathrm{CP}$ which its higher value reduce the motion amplitudes and leads to less speed lost at high speed[8], both are nearly the same value

Although the beam is changed so the length to beam ratio and block coefficient $\mathrm{Cb}$ are changed but both have little influence in motion[8].

\section{References}

1. Christopher, F. Deacutis, and Richard C. Ribb, BALLAST WATER AND INTRODUCED SPECIES: Management Options for Narragansett Bay and Rhode Island, Narragansett Bay Estuary Program, R.I. Department of Environmental Management, (2002).

2. International Maritime Organisation (IMO), International Convention for the Control and Management of Ships' Ballast Water and Sediments, (2004).

3. Japan Ship Technology Research Association, Research and Development of Non Ballast Water Ship, Briefing Report of Research Achievements, (in Japanese.), (2006).

4. Marine Environment Protection Committee, 55th Session, Brief description of the technologies presented, (2006).

5. We Jun, ka Lin Yah: Hull Line Design and Variation for a V-Shape Ballast-Free Ship, Chinese Journal of Ship Research, vol. 5, (2010).

6. Formation Design Systems Pty Ltd, Seakeeper user manual, (2004).

7. O. M. Faltinsen, Hydrodynamics of high-speed marine vehicles, (Cambridge University Press, 2005)

8. K. J. Rawson, Basic ship theory, vol. 2: ButterworthHeinemann, (2001).

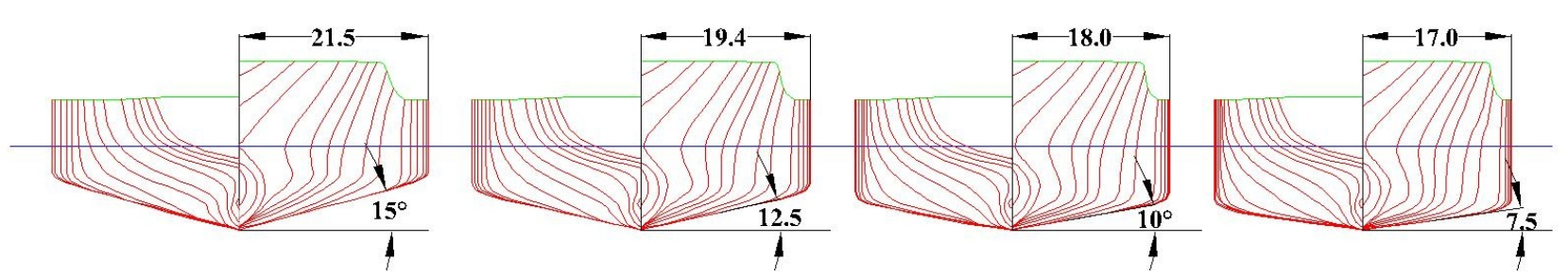

Figure. 3, The Maxsurf models

Table 3, the extracted criteria from (NORDFORSK) to be reference in comparing between the effect of raise angle

\begin{tabular}{c|c}
\hline Criteria & level \\
\hline RMS of Rolling & $6 \mathrm{deg}$ \\
\hline RMS of vertical acceleration & $0.12 \mathrm{~g}$ \\
\hline Dick wetness probability & 0.05 \\
\hline Bottom Slamming probability & 00.016 \\
\hline
\end{tabular}


MATEC Web of Conferences
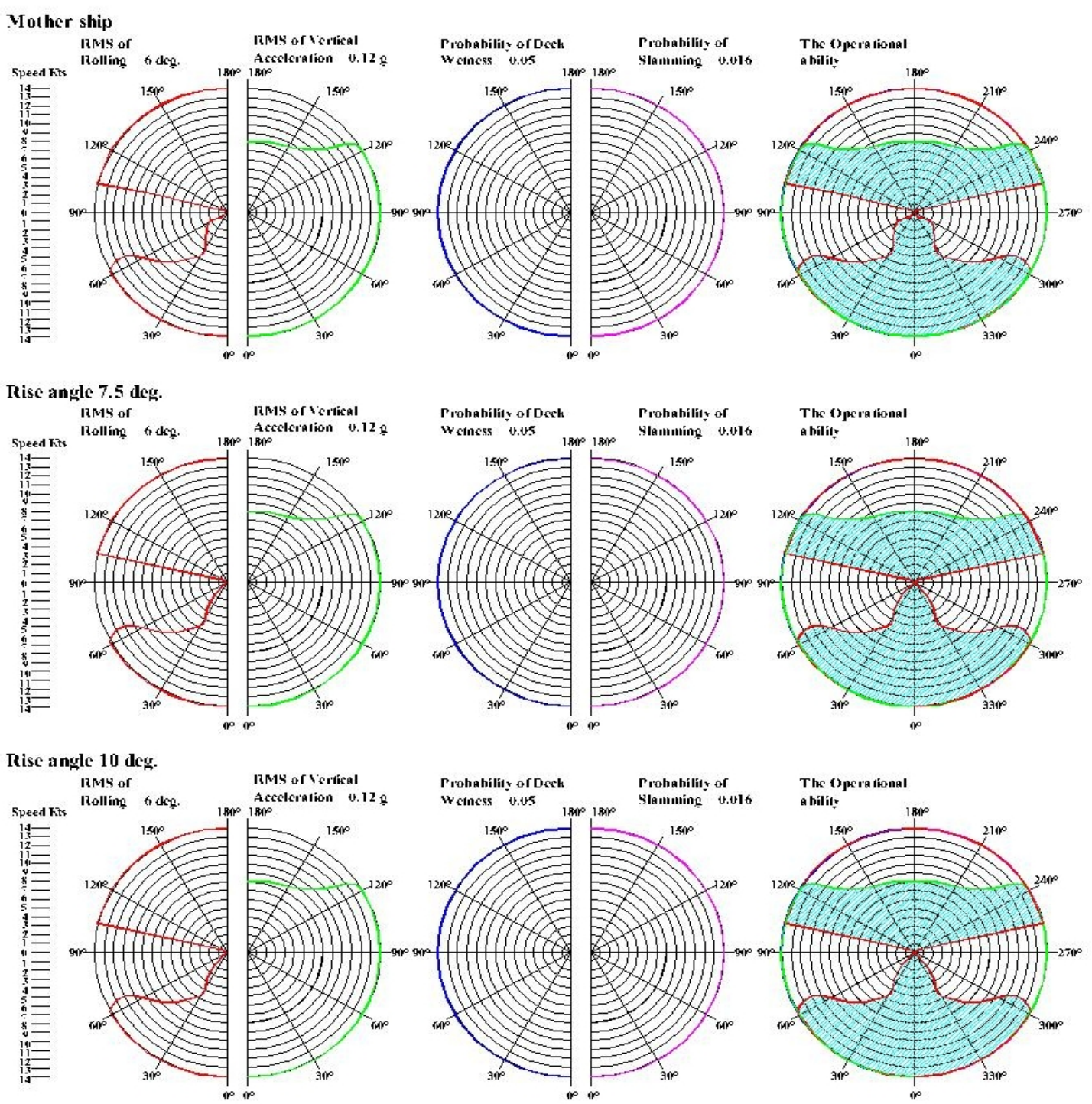

Rise angle 12.5 deg.
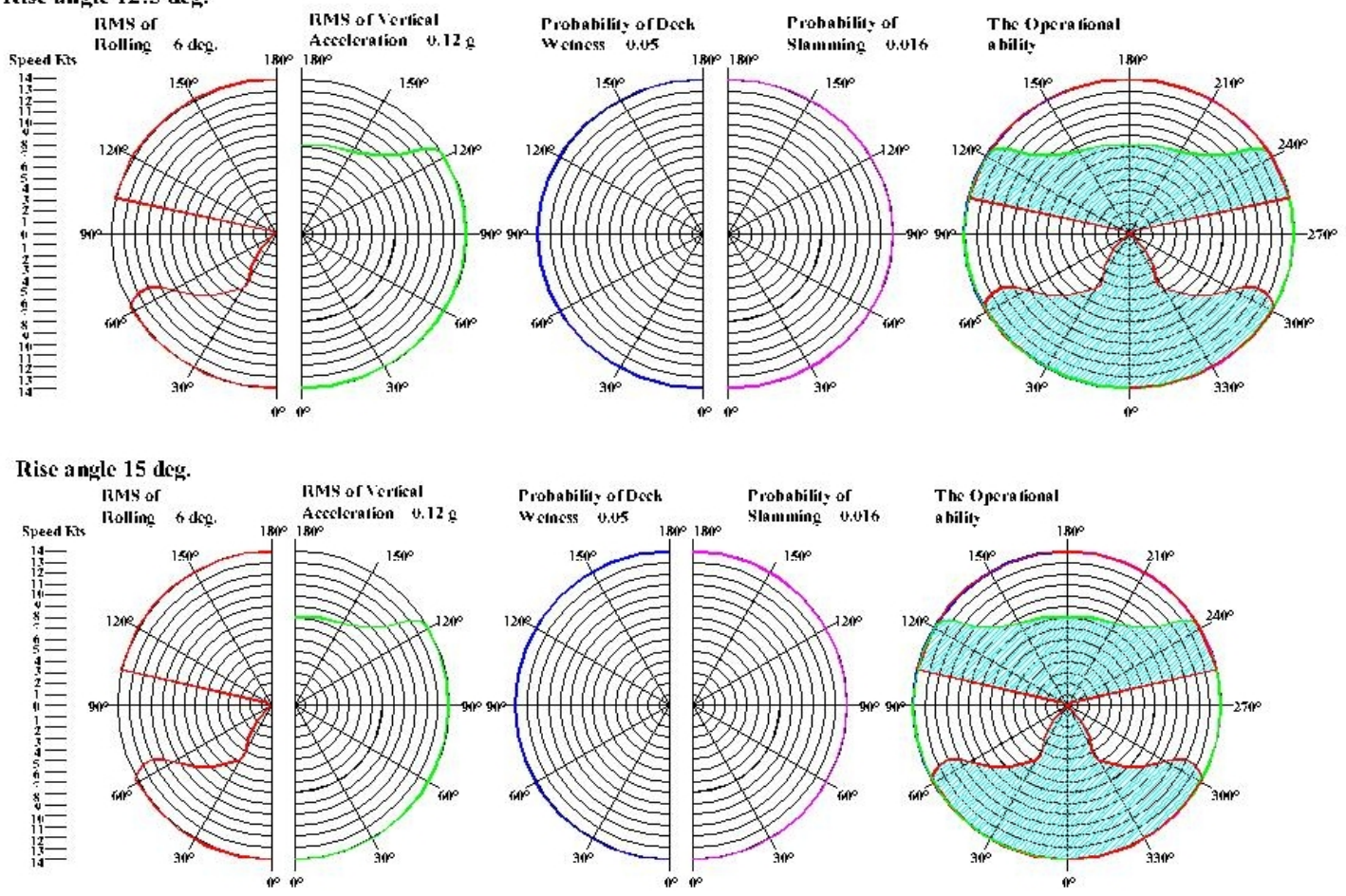

Figure. 4, The seakeeping speed polar diagram for ship with different rise angle 